\title{
Filler shape and volume fraction effect on dynamic compression behaviour of glass filler reinforced epoxy composites
}

\author{
Sarthak S. Singh \\ Department of Aerospace Engineering, \\ Indian Institute of Technology, \\ Kanpur, 208016, India \\ Email: sarthak@iiitk.ac.in
}

\section{Venkitanarayanan Parameswaran}

Department of Mechanical Engineering, Indian Institute of Technology,

Kanpur, 208016, India

Email: venkit@iitk.ac.in

\section{Rajesh Kitey*}

Department of Aerospace Engineering, Indian Institute of Technology,

Kanpur, 208016, India

Email: kitey@iitk.ac.in

*Corresponding author

\begin{abstract}
The effect of filler shape and volume fraction on the dynamic compression behaviour of low volume fraction rigid particle filled polymer composites is demonstrated by performing experiments using split-Hopkinson pressure bar (SHPB) setup. The results indicate negligible influence of spherical particles on the mechanical behaviour of composites due to the large inter-particle separation distance at low volume fractions. On the contrary, the mechanical behaviour of composites is considerably affected by milled-fibres due to the large surface area to volume ratio of slender fillers which significantly decreases the inter-particle separation distance. The computational analysis in combination with experimental observations reveals two competing deformation mechanisms, the constraints provided by fillers to the polymeric chain movements and increasing strain softening in the matrix due to magnified stresses in between the particles. Depending upon the filler volume fraction one of the two mechanisms dominates, thus tailoring post-yield stress vs. strain curves of filled polymers.
\end{abstract}

Keywords: particulate reinforced epoxy composite; dynamic compression; split Hopkinson pressure bar; SHPB.

Reference to this paper should be made as follows: Singh, S.S., Parameswaran, V. and Kitey, R. (2019) 'Filler shape and volume fraction effect on dynamic compression behaviour of glass filler reinforced epoxy composites', Int. J. Materials and Structural Integrity, Vol. 13, Nos. 1/2/3, pp.81-92. 
Biographical notes: Sarthak S. Singh completed his BTech in Mechanical Engineering from the National Institute of Technology (NIT) Rourkela, India. Prior to joining the Department of Aerospace Engineering at the IIT Kanpur as a PhD Scholar, he worked in the Hindustan Petroleum Corporation Limited. His research interest includes mechanical and fracture characterisation of filler reinforced polymer composites at different strain rates.

Venkitanarayanan Parameswaran is a Professor in the Department of Mechanical Engineering at the Indian Institute of Technology Kanpur. He obtained his $\mathrm{PhD}$ in Mechanical Engineering and Applied Mechanics from the University of Rhode Island, USA. His research interests are experimental mechanics, high strain rate phenomena and dynamic failure of materials.

Rajesh Kitey is an Associate Professor in the Department of Aerospace Engineering, Indian Institute of Technology Kanpur (IITK) India. He received his Doctorate from the Auburn University, Auburn, AL, USA. Prior to joining IITK, he was a Postdoctoral Research Associate at the University of Illinois at the Urbana-Champaign. His research interests include quasi-static and dynamic fracture in heterogeneous materials, mechanics of thin films and optical metrology.

This paper is a revised and expanded version of a paper entitled 'Filler shape and volume fraction effect on dynamic compression behavior of glass filler reinforced epoxy composites' presented at Indian Conference on Applied Mechanics (INCAM) 2017, MNNIT Allahabad, 5-7 July 2017.

\section{Introduction}

Rigid particle reinforced polymer composites are used in several engineering applications, ranging from in MEMS and bio-medical equipment to aerospace and civil structures. Such materials in general are subjected to thermo-mechanical loading at various strain rates. Clearly, the mechanical and fracture response of the composites-in-consideration govern the functionality and the reliability of equipments. In general a composite's microstructure is tailored by varying the shape, size, distribution and volume fraction of the filler to enhance its mechanical characteristics. Quite often tensile or flexural experiments are conducted to evaluate the mechanical behaviour of materials. The materials' response to compressive loading is rarely analysed, even if their deformation and failure mechanisms are significantly different when compared to the other loading cases.

The increase in the yield strength of polymers with increasing strain rate has been reported by several researchers (Briscoe and Nosker, 1984; Mayr et al., 1998; Li and Lambros, 2001; Naik et al., 2011). Some of the studies, reporting the effect of fillers on the mechanical characteristics of polymer composites, are reviewed here. Mallick and Broutman (1975) conducted several mechanical tests on $15 \mu \mathrm{m}$ diameter glass bead-epoxy composites with the filler volume fractions up to $40 \%$. It was observed that the compressive yield strength of the composites was enhanced with increase in the volume fraction but the composites' ductility was reduced when compared to the neat epoxy case. Kawaguchi and Pearson (2003) conducted quasi-static compression experiments on glass particle reinforced epoxy composites with mean filler diameter 3.5 
$\mu \mathrm{m}, 15.8 \mu \mathrm{m}$ and $42 \mu \mathrm{m}$, and the volume fraction varying from $10 \%$ to $30 \%$. It was observed that the yield strength increased with increasing filler volume fraction; however it decreased with the samples' exposure to the moisture. Omar et al. (2013) studied the effect of particle size on the compression behaviour of poly-propylene/silica ( $\mathrm{PP} / \mathrm{SiO} 2)$ composites at several strain rates. The particles with average diameters $3 \mu \mathrm{m}, 1 \mu \mathrm{m}, 20$ $\mathrm{nm}$ and $11 \mathrm{~nm}$, were chosen to conduct the study. The composites reinforced with smaller particle sizes $(20 \mathrm{~nm}, 11 \mathrm{~nm})$ showed higher yield-strength, ultimate strength and stiffness when compared to the larger filler cases. It was also observed that the effect of strain rate on the mechanical behaviour of composites reduced with decrease in the filler size. Takeda et al. (2013) investigated the compressional behaviour of MWCT/polycarbonate composites using experimental and numerical approaches for various volume fractions of MWCT at room temperature and liquid nitrogen temperature conditions $(77 \mathrm{~K})$. While the elastic modulus and yield strength was observed to increases with addition of CNTs room temperature and at $77 \mathrm{~K}$; the effect was more pronounced at $77 \mathrm{~K}$. Multi-scale analysis in combination with finite element simulations and analytical molecular structural mechanics predicted well the values of elastic modulus as that obtained from the experiments. Ma et al. (2015) studied both quasi-static and dynamic compression behaviour of silica nanoparticles (20-50 nm in diameter) filled epoxy composites prepared with up to $15 \%$ filler volume fraction. It was observed that the failure stress decreased beyond $10 \%$ filler volume fraction however the increasing silica content increased the energy absorption capacity of composite with lesser craze formation under dynamic loading conditions.

While researchers have reported the studies conducted on spherical and irregular shaped filler composites, the effect of slender fillers on the dynamic compression behaviour is largely unknown. This is due to the complex manufacturing process involved in uniformly distributing short fibres into polymer matrix. In current investigation the dynamic compression tests are conducted using split-Hopkinson pressure bar (SHPB) setup and the effect of filler shape and volume fraction on compression characteristics of glass particle filled epoxy composite is reported. Computational analysis is performed to elucidate the deformation mechanisms involved in the dynamic compression of filler composites.

\section{Experimental details}

\subsection{Material preparation}

The epoxy was prepared by mixing diglycidyl ether of bisphenol A (DGEBA) as resin and triethyltetra-amine (TETA) as hardener in a ratio of 10:1 by weight. Two variants of the glass fillers were used as reinforcement; spherical particles with an average diameter of $34 \mu \mathrm{m}$ and milled fibres with an average length and diameter of $200 \mu \mathrm{m}$ and $16 \mu \mathrm{m}$, respectively. Intermittent mechanical stirring along with degassing and sonication is used to ensure homogenous dispersion of fillers into the epoxy. This mixture with uniformly distributed fillers was then decanted into the cylindrical moulds of $8 \mathrm{~mm}$ diameter and 80 $\mathrm{mm}$ length. The samples were removed after 48 hours and then left as it is in humidity and temperature controlled environment for a period of 30 days for complete curing. The samples (of $8 \mathrm{~mm}$ diameter and $6 \mathrm{~mm}$ length) were prepared with filler volume fractions, 
varied from $0 \%$ to $10 \%$ at a step of $2.5 \%$. The processing details to uniformly disperse spherical and slender fillers into polymer matrix are given in Yesgat and Kitey (2016).

For conducting computational analysis, the physical and the acoustic properties of epoxy matrix is measured separately. The density $(\rho)$ of epoxy, calculated by weighing $10 \mathrm{~mm} \times 10 \mathrm{~mm} \times 10 \mathrm{~mm}$ cubes, is tabulated in Table 1. Ultrasonic thickness gauge Parametrics 35DL (Olympus), in combination with $10 \mathrm{MHz}$ longitudinal and $5 \mathrm{MHz}$ shear wave transducers (M112-RM and V154-RM, respectively) are employed to measure the wave speeds using pulse echo method. While the longitudinal $\left(C_{d}\right)$ and shear $\left(C_{s}\right)$ wave speeds in the epoxy were measured as $2,610 \mathrm{~m} / \mathrm{s}$ and $1,220 \mathrm{~m} / \mathrm{s}$, respectively, these were taken as $5,940 \mathrm{~m} / \mathrm{s}$ and $3,750 \mathrm{~m} / \mathrm{s}$, respectively for glass beads (Wang et al., $2003)$ in the present study. The dynamic elastic modulus $\left(E_{d}\right)$ and the Poisson's ratio $\left(v_{d}\right)$, determined by applying the plane strain equation, are included in Table 1.

Table 1 Elastic properties of the materials used in computational modelling

\begin{tabular}{lccc}
\hline Material & Density ' $\rho$ ' $\left(\mathrm{kg} / \mathrm{m}^{3}\right)$ & Elastic modulus ' $E_{d}$ ' $(\mathrm{GPa})$ & ${\text { Poisson's ratio ' } v_{d} \text { ' }}^{\text {Epoxy }}$ \\
\hline Glass beads & 2,195 & 4.838 & 0.36 \\
Steel & 7,200 & 72.27 & 0.168 \\
\hline
\end{tabular}

\subsection{Experimental method}

The SHPB setup, employed to conduct the dynamic compression experiments, consists of a striker, an incident bar and a transmitted bar, all made of maraging steel and have the diameter of $20 \mathrm{~mm}$ (see, Figure 1). A pair of strain gauges, mounted diametrically opposite at the mid-length of the incident and transmitted bars, are used to record the incident, reflected and transmitted strain signals. The test specimen is sandwiched between the incident and the transmission bars. The bar ends, holding the sample, are lubricated to minimise the friction. A compressive pulse of duration $160 \mu \mathrm{s}$ [see, Figure 2(a)] is developed in the incident bar when a striker impacts the incident bar at a velocity of $13 \mathrm{~m} / \mathrm{s}$ which propagates towards the sample interface. A part of the stress pulse reflects back into the incident bar and the rest is passed into the transmission bar through the composite sample. The deformation in the specimen is captured through an ultra-high speed camera, operating at $10^{5}$ frames per second. The strain histories in the incident and transmission bars are recorded at a sampling rate of $1 \mathrm{MHz}$. The strain rate $\left(\dot{\varepsilon}_{S}\right)$, strain $\left(\varepsilon_{s}\right)$ and the stress $\left(\sigma_{s}\right)$ histories in the specimen are obtained by using the following relationship (Lindholm, 1964). The representative strain histories in the incident and transmission bars are plotted in Figure 2 (a). Corresponding variations of stress and strain rate with the strain, shown in Figure 2(b), are determined by using the following equations.

$$
\begin{aligned}
& \dot{\varepsilon}_{S}(t)=-2 C_{b} \frac{\varepsilon_{R}(t)}{l_{S}} \\
& \varepsilon_{S}(t)=-2 \frac{C_{b}}{l_{S}} \int_{0}^{t} \varepsilon_{R}(t) d t
\end{aligned}
$$




$$
\sigma_{S}(t)=\frac{E_{b} A_{b}}{A_{S}} \varepsilon_{T}(t) ; C_{b}=\sqrt{\frac{E_{b}}{\rho_{b}}}
$$

Here $C_{b}, E_{b}$ and $\rho_{b}$, represent the elastic wave speed, Young's modulus and density of the bar, respectively. The cross sectional area of the specimen and bars are given by $A_{S}$ and $A_{b}$, respectively whereas $l_{S}$ represents the length of the specimen. The transmitted energy raises the stress level to the yield point in the sample [see point ' $Y$ ' in Figure 2(b)] which is followed by gradual drop in the stress value. The instantaneous drop of the stress at a strain value of 0.25 indicates that the compressive pulse has completely transmitted through the specimen. Throughout the experiment the specimen was loaded at a nominal strain rate of $1,700 / \mathrm{s}$ [Figure 2(b)].

Figure 1 Schematic representation of SHPB setup and specimen dimensions

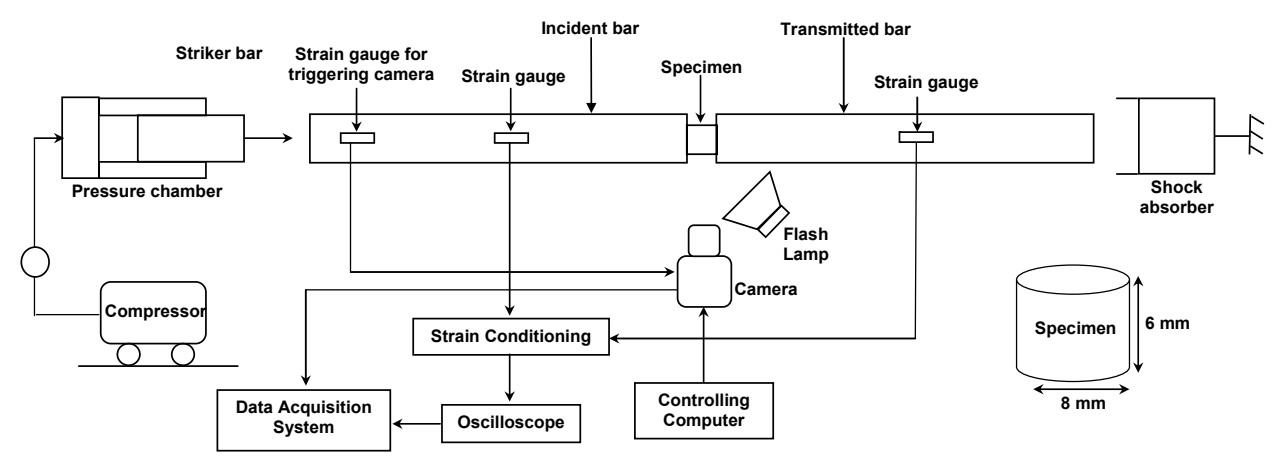

\section{Results and discussions}

The effect of filler volume fraction on the dynamic compression behaviour of reinforced composites is illustrated in Figure 3. While in spherical reinforcement cases [see, Figure 3(a)] similar stress vs. strain curves are obtained for all considered volume fractions, the plots show marginal increase of yield strength in composites ( $245 \mathrm{MPa})$ when compared to the neat epoxy case (225 MPa). Even (nearly the same) post-yield plateau stress of $\sim 180 \mathrm{MPa}$ in between 0.1 and 0.2 strain region is observed for all volume fraction cases. Unlike nearly the same yield strength values in spherical reinforcement case, the yield strength of milled-fibre composites shows increasing trend with filler volume fraction [see, Figure 3(b)]. This is attributed to the constraints introduced by the filler particles to the polymeric chain movements (Martin et al., 2007; Jordan et al., 2014). In case of spherical reinforcement cases, the particles are significantly far from each other due to the considered low volume fractions. The particles provide very small resistance to the deformation of the surrounding matrix while subjecting itself to the rigid body motion. On the other hand the inter-particle separation in milled-fibre composites is considerably small due to the large slenderness and relatively higher surface area to volume ratio of fillers. The closeness of fillers and their mesh-like distribution significantly impedes the deformation of surrounding matrix which results into increasing the yield strength of milled-fibre composites with the increasing filler volume fraction. Interestingly, the post-yield plateau stress in milled-fibre 
composites which increases with filler volume fraction is evident only up to $5 \%$ filler volume fraction case. With further increase in reinforcement the post-yield stress monotonically decreases with increasing strain value, more rapidly at higher volume fractions.

Figure 2 (a) Strain histories recorded by the strain gauges mounted on the incident and transmitted bars respectively (b) Variation of stress and strain-rate with respect to strain (see online version for colours)

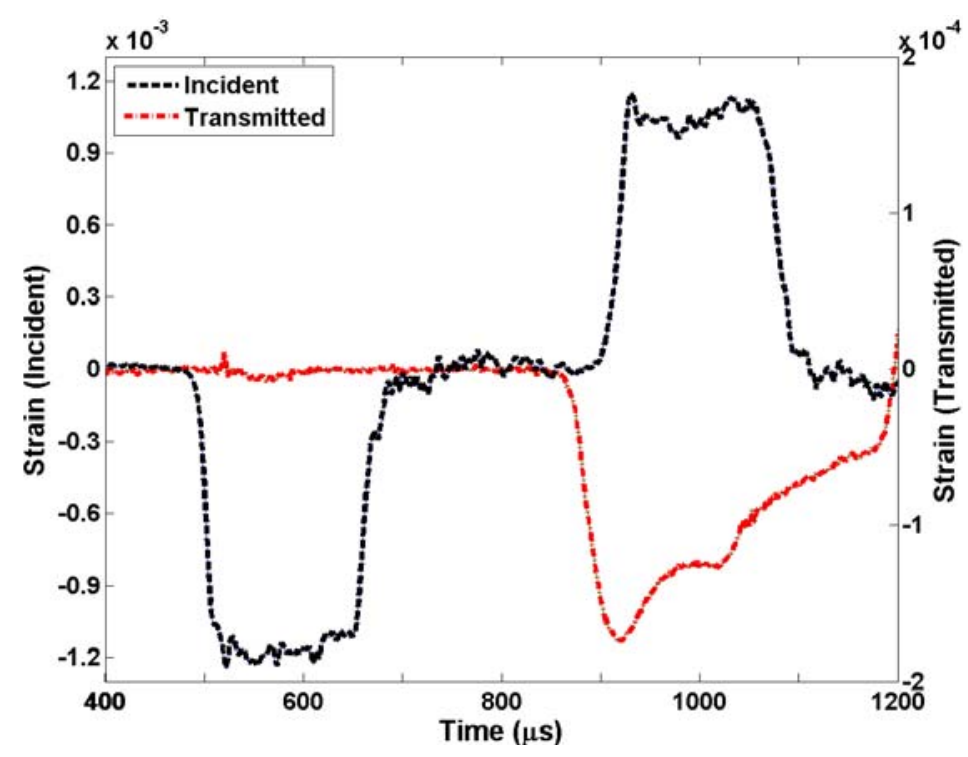

(a)

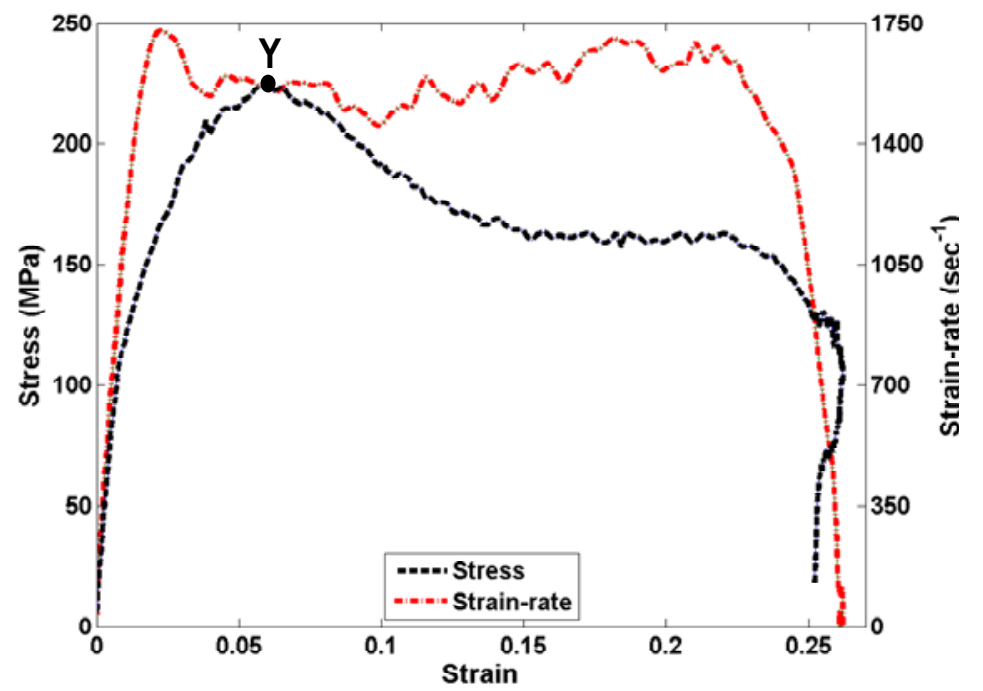

(b) 
Figure 3 Stress-strain curve under dynamic compression for, (a) spherical particles, and (b) milled fibre reinforced epoxy composites (see online version for colours)

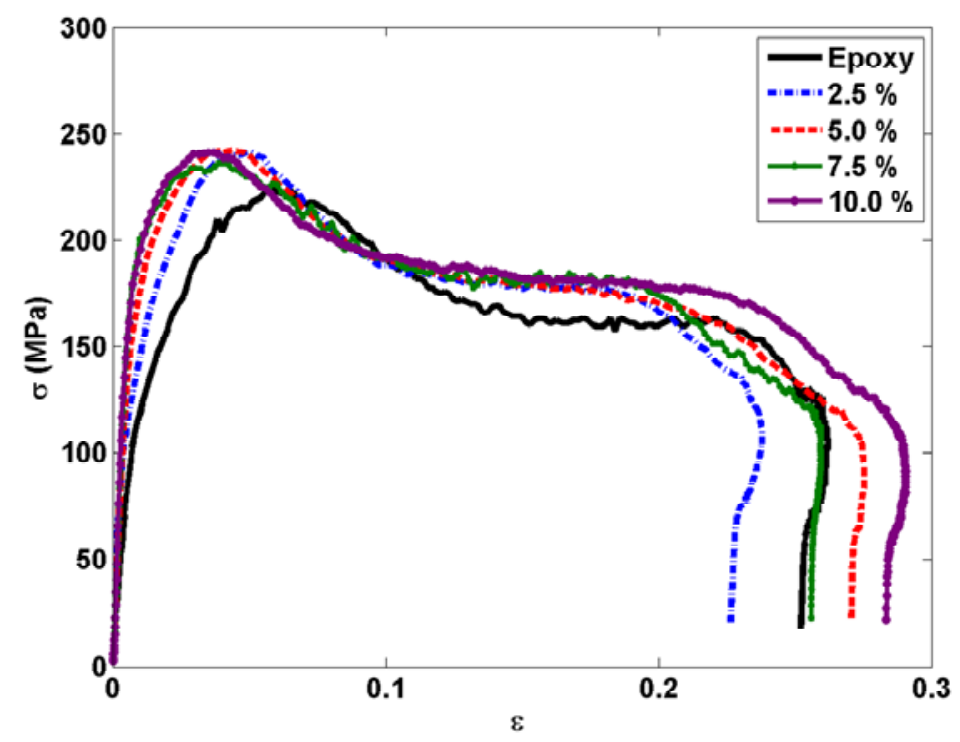

(a)

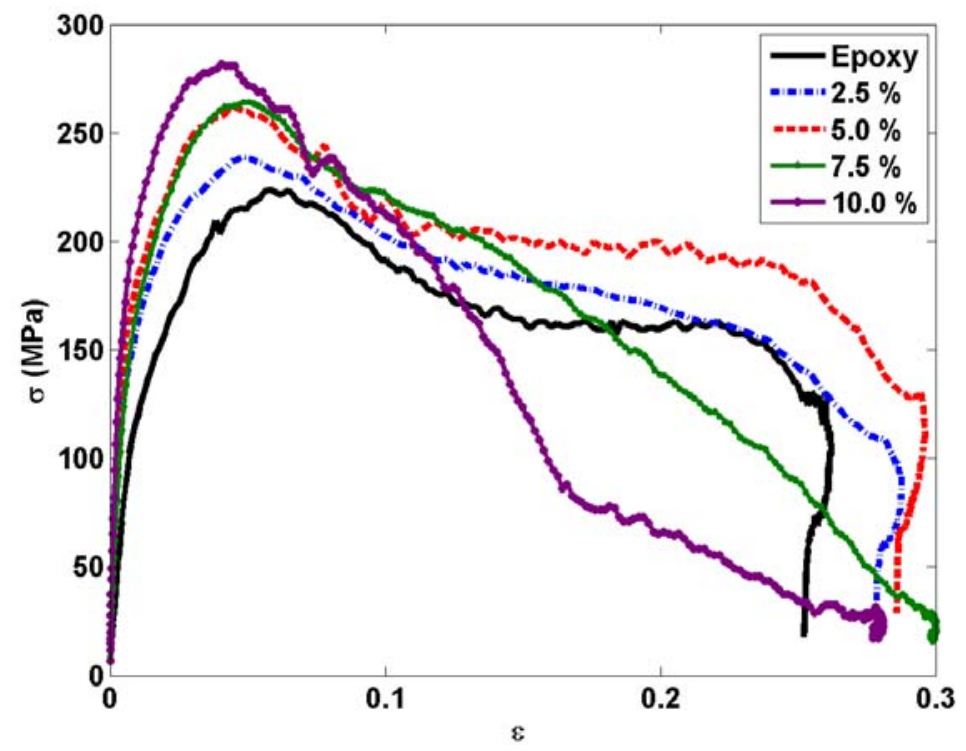

(b)

\subsection{Computational analysis}

Distinct filler shape effect on the dynamic compression behaviour is evident from the experimental data. While the filler volume fraction significantly influenced the strain history in the milled-fibre composites, in spherical particle case no such effect was 
evident. To get more insight into the effect of fillers on the local stress fields a two dimensional finite element simulation is carried out in ABAQUS-6.12. Figure 4(a) illustrates the schematic representation of model configuration. The $6 \mathrm{~mm} \times 5 \mathrm{~mm}$ epoxy matrix with two symmetrically located circular solid glass inclusions, aligned with the wave propagation direction, is sandwiched between the incident and transmission bars. The two steel bars of $20 \mathrm{~mm}$ width are partially modelled with infinite elements CINPS4 (ABAQUS-6.12 analysis user manual) at the bar ends. A trapezoidal velocity profile with the rise, dwell and fall times similar to that obtained in the experiments is applied at the intermediate nodes of the incident bar. The dynamic explicit integration scheme with plane stress elements CPS4R is employed in the simulations. The element size is chosen based on a convergence study. The physical and elastic properties of elements used in the simulations are tabulated in Table 1.

Figure 4 Schematic representation of (a) SHPB setup modelled in ABAQUS, (b) orientation of the particles with respect to the horizontal axis and (c) representative von-Mises stress field developed around inclusions (see online version for colours)

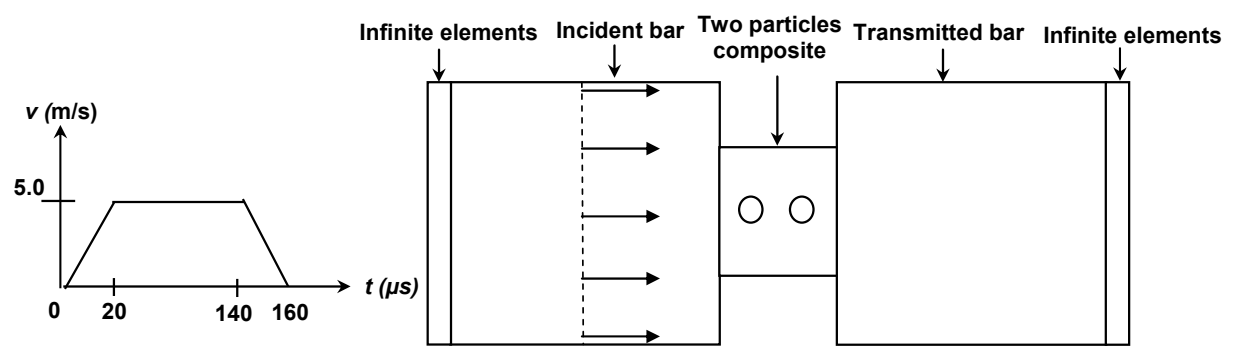

(a)

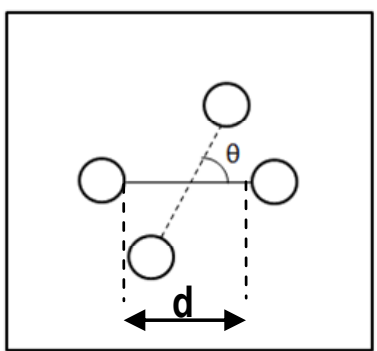

(b)

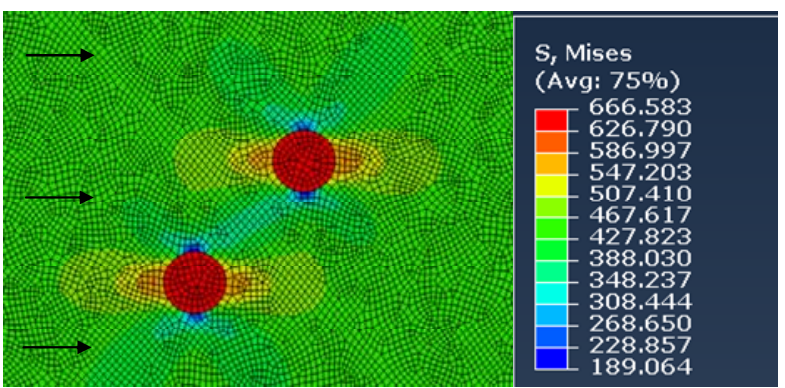

(c)

Three different inclusion diameters, $150 \mu \mathrm{m}, 300 \mu \mathrm{m}$ and $600 \mu \mathrm{m}$, are chosen to model the composite geometry whereas the inter-particle separation, $d$ [see, Figure 4(b)], varied from $0.15 \mathrm{~mm}$ to $3.2 \mathrm{~mm}$. A highly refined mesh is employed around the inclusions to capture the precise state of stress in the matrix near the interface. A representative von-Mises stress contours, obtained for the case when the inclusion array is oriented at $45^{\circ}$ from the loading axis, is illustrated in Figure 4(c). In the depicted stress field centre-to-centre distance between $300 \mu \mathrm{m}$ diameter inclusions are considered to be $0.5 \mathrm{~mm}$. From Figure 4, it is evident that the contours extend along the loading axis whereas they shrink in the transverse direction. 
Figure 5 (a) Effect of inter-particle separation and (b) filler orientation on the normalised average maximum von-Mises stress in between the inclusions (see online version for colours)

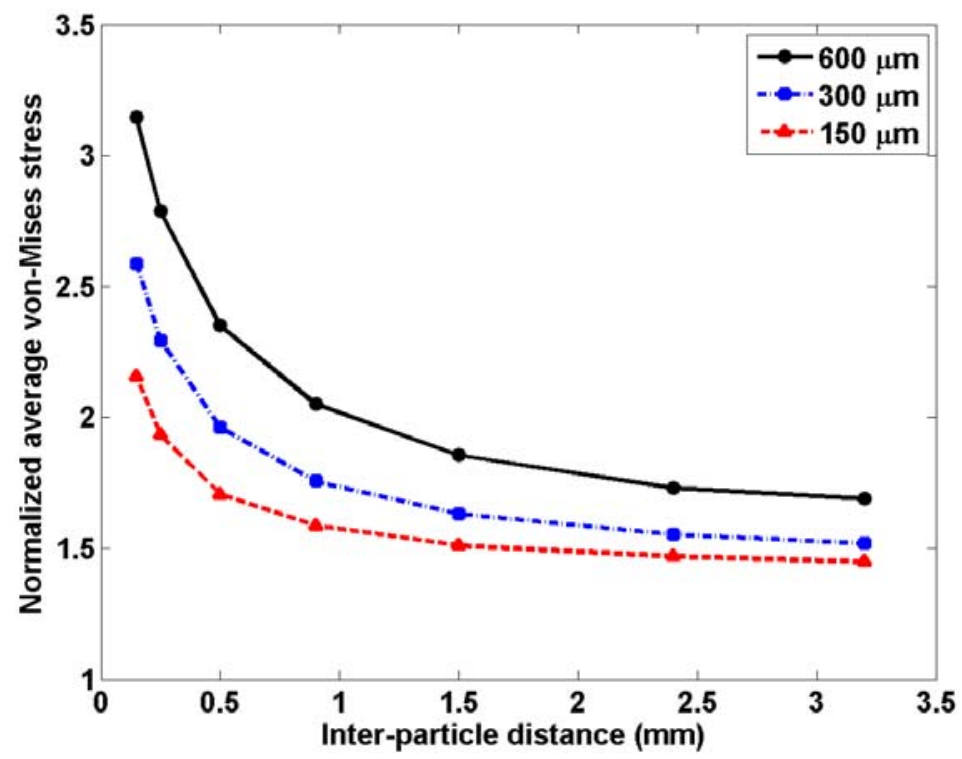

(a)

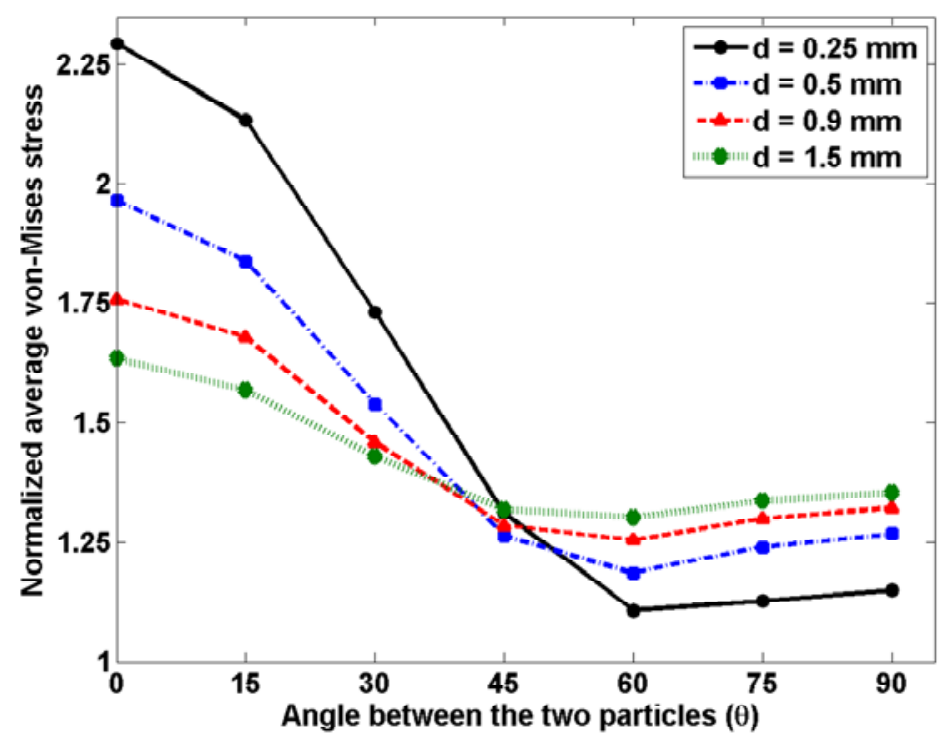

(b)

During wave propagation the maximum average von-Mises stress in the matrix material is calculated along the line, joining the inclusion centres. The stress is then normalised with the corresponding value for the neat epoxy case. In Figure 5(a) the normalised (average maximum) von-Mises stress is plotted with inclusion separation distance for various inclusion diameters. The plots suggest that the stress in the matrix region in 
between the inclusions increases with increasing inclusion diameter but its values decrease with increasing inter-particle separation distance.

To study the effect of filler distribution on the localised stress field the two inclusions are oriented from $0^{\circ}$ to $90^{\circ}$ as shown in Figure 4(b). The $300 \mu \mathrm{m}$ diameter inclusions are considered in the simulations with inter-particle distance ranging from $0.25 \mathrm{~mm}$ to $1.5 \mathrm{~mm}$. As discussed earlier, the normalised average maximum von-Mises stress along the line joining the inclusions are evaluated and plotted with filler orientation $(\theta)$ in Figure 5(b). From the plots it is evident that the magnitude of stress decreases monotonically with increasing inter-particle separation as well as with $\theta$ until $45^{\circ}$ orientations. The stress values appear to be stabilising with further increase in orientation angle.

\subsection{Deformation mechanisms}

Computational analysis in combination with experimental observations reveals very interesting deformation mechanisms in filled polymer composites. From Figure 3(b) it is evident that the post-yield stress variation does not show consistency with the variation of filler volume fraction, indicating the presence of multiple deformation mechanisms. Re-analysing the computational data presented in Figure 4(a) suggests that a critical inter-particle separation distance can be defined below which the stress level in between the inclusions increases nearly exponentially whereas the decreasing von-Mises stress tends to stabilise if the distance is increased beyond this critical value. Due to extreme dynamic loading being an adiabatic process (Garg et al., 2008) the localised temperature in matrix increases with increasing stress magnitude. Clearly, the smaller inter-particle separation would lead to higher strain softening in the polymer matrix because of larger stress magnitude. On the contrary more number of fillers provides higher resistance to post-yield free movement of polymeric chains which enhances strain hardening in the matrix material. No specific trend in the stress-strain behaviour of milled-fibre composites [see, Figure 3(b)] is anticipated to be due to the competing deformation mechanisms. Up to $5 \%$ filler volume fraction the constraints to the polymeric chain movement dominate which leads to higher strain softening stress at larger filler volume fraction. With further increase in the filler volume fraction the strain softening mechanism due to higher localised stress (or temperature) dominates which results in monotonically decreasing stress in the post-yield region. Due to low volume fraction and comparatively smaller surface area to volume ratio of fillers in spherical particle composites the fillers are significantly apart from each other. Therefore, both deformation mechanisms play negligible role and the deformation mostly remains matrix dominated.

\section{Conclusions}

Dynamic compression experiments are conducted on glass particle filled epoxy composites using SHPB setup. Two inclusion variants, spherical particles of average diameter $34 \mu \mathrm{m}$ and cylindrical fillers (milled fibres) of average length and diameter, $200 \mu \mathrm{m}$ and $16 \mu \mathrm{m}$, respectively, are reinforced into an epoxy system at volume fractions ranging from $0 \%$ to $10 \%$ at a step of $2.5 \%$. Negligible influence of spherical particles on the stress vs. strain curves of composites is attributed to the large inter-particle separation distance. On the contrary, the mechanical behaviour of 
composites is considerably affected by milled-fibres due to the relatively larger surface area to volume ratio of fillers which significantly decreases the inter-particle separation distance. The computational analysis indicates that the stress magnification in between the inclusions exponentially increases below a critical inter-particle separation distance. Numerical modelling in combination with experimental observations indicates two competing deformation mechanisms in filler composites. First, the constraints provided by the fillers to polymeric chain movements which increase post-yield strain hardening and second, the increased strain softening due to the magnified stresses in the epoxy. Depending upon the filler volume fraction one of the two mechanisms dominates.

\section{Acknowledgements}

Authors would like to thank Aeronautics Research \& Development Board (ARDB) for supporting this research through grant DARO/08/10516629/M/I.

\section{References}

Briscoe, B.J. and Nosker, R.W. (1984) 'The influence of interfacial friction on the deformation of high density polyethylene in a split Hopkinson pressure bar', Wear, Vol. 95, No. 3, pp.241-262.

Garg, M., Mulliken, A.D. and Boyce, M.C. (2008) 'Temperature rise in polymeric materials during high rate deformation', Journal of Applied Mechanics, Vol. 75, No. 1, p.11009.

Jordan, J.L., Spowart, J.E., Kendall, M.J., Woodworth, B. and Siviour, C.R. (2014) 'Mechanics of particulate composites with glassy polymer binders in compression', Philosophical Transactions of the Royal Society of London A: Mathematical, Physical and Engineering Sciences, Vol. 372, p.20130215.

Kawaguchi, T. and Pearson, R.A. (2003) 'The effect of particle-matrix adhesion on the mechanical behavior of glass filled epoxies: part 1. A study on yield behavior and cohesive strength', Polymer, Vol. 44, No. 15, pp.4229-4238.

Li, Z. and Lambros, J. (2001) 'Strain rate effects on the thermomechanical behavior of polymers', International Journal of Solids and Structures, Vol. 38, No. 20, pp.3549-3562.

Lindholm, U.S. (1964) 'Some experiments with the split Hopkinson pressure bar', Journal of the Mechanics and Physics of Solids, Vol. 12, No. 5, pp.317-335.

Ma, P., Jiang, G., Li, Y. and Zhong, W. (2015) 'The impact compression behaviors of silica nanoparticles - epoxy composites', Journal of Textile Science and Technology, Vol. 1, No. 1, p.1.

Mallick, P.K. and Broutman, L.J. (1975) 'Mechanical and fracture behaviour of glass bead filled epoxy composites', Materials Science and Engineering, Vol. 18, No. 1, pp.63-73.

Martin, M., Hanagud, S. and Thadhani, N.N. (2007) 'Mechanical behavior of nickel + aluminum powder-reinforced epoxy composites', Materials Science and Engineering: A, Vol. 443, No. 1, pp.209-218.

Mayr, A.E., Cook, W.D. and Edward, G.H. (1998) 'Yielding behaviour in model epoxy thermosets - I. Effect of strain rate and composition', Polymer, Vol. 39, No. 16, pp.3719-3724.

Naik, N.K., Shankar, P.J., Kavala, V.R., Ravikumar, G., Pothnis, J.R. and Arya, H. (2011) 'High strain rate mechanical behavior of epoxy under compressive loading: experimental and modeling studies', Materials Science and Engineering: A, Vol. 528, No. 3, pp.846-854. 
Omar, M.F., Akil, H.M. and Ahmad, Z.A. (2013) 'Particle size - dependent on the static and dynamic compression properties of polypropylene/silica composites', Materials \& Design, March, Vol. 45, pp.539-547.

Takeda, T., Narita, F., Kuronuma, Y. and Shindo, Y. (2013) 'Numerical and experimental study on the response of multi-walled carbon nanotube/polymer composites under compressive loading, International Journal of Materials and Structural Integrity, Vol. 7, Nos. 1-3, pp.4-21.

Wang, J., Sottos, N.R. and Weaver, R.L. (2003) Thin Film Adhesion Measurement by Laser Induced Stress Waves, Department of Theoretical and Applied Mechanics (UIUC).

Yesgat, A.L. and Kitey, R. (2016) 'Effect of filler geometry on fracture mechanisms in glass particle filled epoxy composites', Engineering Fracture Mechanics, July, Vol. 160, pp.22-41. 